\begin{tabular}{|c|c|c|}
\hline & Int.J.Curr.Microbiol.App.Sci (2021) 10(12): 91-110 & \\
\hline & $\begin{array}{l}\text { International Journal of Current Microbiology and Applied Sciences } \\
\text { ISSN: 2319-7706 Volume } 10 \text { Number } 12 \text { (2021) } \\
\text { Journal homepage: http://www.ijcmas.com }\end{array}$ & $\$ 0$ \\
\hline $\begin{array}{l}\text { EXCELLENT } \\
\text { PUBLISHERS }\end{array}$ & & \\
\hline
\end{tabular}

Review Article

https://doi.org/10.20546/ijcmas.2021.1012.011

\title{
Anona Genus : Phytochemical, Anticancer and Activity Structure Relationship
}

\author{
Lusi Madona*, Afrizal and Mai Efdi
}

Universitas Andalas Jurusan Kimia, Fakultas Matematika dan Ilmu Pengetahuan Alam, Universitas Andalas Kampus Limau Manis, Padang, Sumatera Barat, 25163, Indonesia

*Corresponding author

\section{A B S T R A C T}

\section{Keywords}

Annona, Active

Compound, Anti

Cancer, Structure-

Activity

Relationship

Article Info

Received:

02 November 2021

Accepted:

30 November 2021

Available Online:

10 December 2021
The Annonagenus, consisting of 119 species, has been continuously researched and proven to have various pharmacological activities such as anticancer, antioxidant, antiinflammatory, antibacterial and so on. Annona plants such as Annona cherimolia Mill, Annona Reticulate, Annona Squamosa, Annona muricata $L$ have antioxidant, antimicrobial, anti-inflammatory, antihelmintic, antipyretic, antihyperglycemic, analgesic, wound healing, and cytotoxic effects caused by the presence of active compounds such as acetogenin, alkaloids. And terpenoids whose role as treatment or prevent anti-cancer. Active compounds in inhibiting or preventing cancer cells are mostly found in the leaves, seeds and fruit of the Annona plant. The anticancer or antitumor activity of bioactive compounds is related to the structure of these compounds. The large number of hydroxyl groups and supported by the hydroxyl position flanking the $\gamma$-lactone ring and the stereochemical arrangement of the THF ring determines the effectiveness of cytotoxic activity (the stereochemical arrangement of the THF ACG ring, threo/trans/erythro is more active than threo/trans/threo), the presence of hydroxyl groups at the tail of the ACG carbon chain and for alkaloids in the presence of 1,2-methylenedioxy and methylated nitrogen.

\section{Introduction}

The genus Annona consists of 119 plant species, most of which grow in the tropics; One of them is soursop (Annona muricata), Annona cherimola, Annona reticula and Annona squamosal. Annona species are moderately erect shrubs or small trees that grow to 5-11 $\mathrm{m}$ tall depending on the species and region they inhabit, and are iron to grayish, and tomentose when young, but then become bare (Badrie et al., 2010, Quilez et al., 2018). Ethnobotanically, plants of this genus play an important role as food and medicinal products (Tellez et al., 2018). This Annona species has been used as medicine by the community such as parasite disorders, infections, inflammation, diabetes and cancer (Mishra et al., 2013). This is related to the content of bioactive compounds contained in these plants, namely the presence of acetogenins, alkaloids, essential oils, 
flavonoids, terpenoids, and (oliveira et al., 2002; Barbalho et al., 2012). Acetogenins (ACGs) are the major constituents of the genus Annona and have been found to possess various pharmacological properties including antitumor, immunosuppressive, pesticide, antiprotozoal, antimicrobial, antimalarial, anthelmintic, and antiviral properties. (Barbalho et al., 2012; Asar et al., 2015) (nugraha)The number of studies that have been carried out on Annona plants is needed to make a summary of the research results. So with this review, it is intended to provide knowledge about the active compounds in Annona cherimola, Annona muricata, Annona reticula and Annona squamosa. Where there are active compounds that are anticancer or antitomur and considering the high price of cancer drugs. The relationship of anticancer properties or tumors to the structure of these compounds. Therefore, it is necessary to collect and review the research that has been conducted done before. Journals collected from 2000-2020, have a minimum of H-Index 17 , and has a quartile score of 1 to 3 .

\section{Phytochemical Study of Secondary Metabolites of Annona Genus}

Annona contains a variety of phytochemicals in roots, leaves, twigs, bark, seeds, and fruit flesh. The main bioactive compounds include acetogenins (ACGs), alkaloids (ALKs), phenolic compounds, essential oils (EO), cyclopeptides (CPs), carotenoids, and amino acids. Flavonoids isolated from aqueous extract of Annona squamosa have shown antimicrobial activity (Kotkar et al., 2002) Podophyllptoxin (a non-alkaloid toxin lignan compound) and its demethyl derivatives $4^{\text {ce }}$ demethylpodophyllotoxin, liriodenine and (-)kaur-16-en-19 -oic acid was also isolated from the (Hatano et al., 2002). GC analysis of fatty acid methyl esters (FAMEs) of the seed oil revealed the presence of saturated fatty acids such as hexadecanoic acid (palmitic acid), octadecanoic acid (stearic acid), and unsaturated fatty acids such as octadecenoic acid (oleic acid), eicosanoic acid (gondoic acid).) (Alassane et al., 2004). Extraction of various parts of Annona squamosa in different solvents revealed the presence of alkaloids, flavonoids, phenols, carbohydrates, saponins, sterols and tannins (Agrawal et al., 2012; Ashok et al., 2010). Annona Squamosa, a drought-resistant multipurpose evergreen tree commonly known as "Custard Apple" to the Annonaceae family, is gaining increasing importance due to its therapeutic potential (Vyas et al., 2012). The fruit of this plant is edible. Usually, the leaves are used as a vermicide, to treat cancerous tumors and applied to abscesses, insect bites and other skin complaints, then root bark scrapings are used for toothaches (Saha, 2011). Custard apples are reported to have various beneficial chemical compounds such as alkaloids, isomeric hydroxyl ketones from leaves, acetogenin, samaquasine, annonacin and annonastatin from seeds, acetogenin, and squamone from bark. Various Research shows that custard apples have antibacterial activity. antidiabetic, antitumor, antimalarial, anthelmintic, antigenotoxic, and hepatoprotective (Singh et al., 2019).

Annona cherimola Mill seed extract, known to have strong toxic activity, induces apoptosis in AML cell lines by activation of both extrinsic and intrinsic pathways (Haykal et al., 2019). Annona cherimola Mill. (Custad apple) is widely used in traditional and folkloric medicine systems, because it contains many bioactive compounds such as acetogenins annonaceous, annocherine A, cherianoine, annocherine B, cherimoline, annomolin, romucosine $\mathrm{H}$, anonaine and others (Jamkhand et al., 2017). Cherianoine, annocherine B, Annona muricata $L$ is a tropical fruit tree of the genus Annonaceae. Annona muricata $L$ is also known as soursop plant. Soursop seeds are rich in oil, vitamins, and low in toxins 
(tannins, phytates, and cyanides) (Badire et al., 2010).

Annonacin is the most abundant acetogenin isolated from the leaves of A. muricata (Champy et al., 2009). Annona muricata leaves produce crude extract with a concentration of $0.125 \%$ of the total alkaloids from chloroform extraction. These alkaloids were identified as anonaine, isolaureline, xylopine, colaurine, benzyltetrahydroisoquinoline alkaloids (Fofana et al., 2011). In further research, Fofana produced Nmethylcoclaurine, asimilobin, remerine, isoboldin, and liriodenine. The leaves contain alkaloids with the highest concentration compared to roots, stems and fruit (Fofana et al., 2011, 2012). Isoquinoline, aporphine, and protoberberine are types of alkaloids often isolated from Annona muricata (Mohanty et al., 2008).

Phytochemical studies on different parts of Annona muricata have isolated and identified secondary metabolites, such as: acetogenins, alkaloids, phenolic compounds, and megastigman (Yang et al., 2015; Coria-Téllez et al., 2016). The Annonaceous acetogenins are most abundant in leaves, a unique group of long-chain fatty acid derivatives derived from the polyketide pathway (Sun et al., 2016) Using in vitro studies, extracts and phytochemicals of A. muricata have been characterized as antimicrobial, antiinflammatory, anti-inflammatory and antiinflammatory. protozoa, antioxidants, and insecticides (Cario-Tellez et al., 2016). The results obtained in this study indicate that the consumption of soursop fruit can do a good alternative to prevent diseases such as prostate and cervical cancer (Raybaudi-Massilia et al., 2015).

Annona reticulate is a fruit native to Central America which has become an important crop because of its delicious taste, high flesh content, nutritional value and antioxidant properties (Julián-Loaeza et al., 2011). Annona reticulate is a plant that is very clearly seen in the Ayurvedic system of medicine for the treatment of various diseases (A. Jayaprakash, 2017).

\section{Anti Cancer Activity}

Annona muricata leaf extract is an effective therapeutic agent for human liver cancer cells Huh-7 (Adewole and Ojewole, 2008). HeriSusilo et al., 2012 stated that this extract could inhibit the population of MCF-7 cells with an IC50 value of $97 \mu \mathrm{g} / \mathrm{ml}$ and showed a cytotoxic level of $2.5 \mathrm{~g} / \mathrm{ml}$ for Leukemia cancer cells, K-562, a chronic myelogenous cell line. (Ezirim et al., 2013). In addition, Annona muricata leaves can cause higher cell death $(2000 \mathrm{~g} / \mathrm{ml}$ has $91.86 \% ; 15.625 \mathrm{~g} / \mathrm{ml}$ has 2.68\%) (Parma AO et al., 2013). In 2014, the distribution of Annona leaf extract muricata showed increased levels of ROS (Reactive Oxygen Species) thereby inhibiting A549 cells (human basal alveolar epithelial cell adenocarcinoma). Intracellular ROS play an important role in cancer cell death. (Zorofchian et al., 2014a). In another report, this extract strongly inhibited colon cancer cells with IC50 values of $11.43 \pm 1.87 \mathrm{~g} / \mathrm{ml}$ and $8.98 \pm 1.24 \mathrm{~g} / \mathrm{ml}$ against HT-29 and HCT116 cells, respectively (Zorofchian et al., 2014b). On the other hand, it can help stabilize metastatic breast cancer for 5 years and inhibit the action of breast cancer cell lines, MCF-7, MDA-MB-231 and 4T1 (Hansra, 2014, Syed $\mathrm{N}$ et al., 2016). The ethanol extract of Annona muricata leaves with IC50 values $=335.85$, $248.77,202.33 \mu \mathrm{g} / \mathrm{mL}$ for EACC, MDA and SKBR3 cell lines, respectively, and did not show anticancer effect on normal spleen cells, while aqueous extract did not ( Gavamukulya et al., 2014). Anti-proliferative and apoptotic effects against hyperplastic benign prostate tumor cells (BPH-1) shown by Annona leaf extract. Muricata in vivo (Asare et al., 2015). 
In rats, A. muricata leaves also showed chemopreventive potential against azoxymethane-induced colonic aberrant crypt foci. (Moghadamtousi et al., 2015c). Another investigation reported that in liver cancer HepG2 cells, ethanol extract of A. muricata leaves induced apoptosis through the endoplasmic reticulum stress pathway (Liu et al., 2016). Proteomic analysis found 14 proteins associated with the extract in triggering apoptosis; including upregulation in HSP70-associated protein, GRP94, and DPI 5 expression levels, which further confirmed the work of the endoplasmic reticulum stress pathway by the extract. This investigation proved the potential of $A$. muricata leaf extract as an effective anticancer agent. Then, $A$. muricata extract was found to suppress HL-60 cell proliferation by inducing morphological changes, G0/G1 cell phase arrest, impaired cell viability and mitochondrial membrane potential loss (Pieme et al., 2014). These findings prove that $A$. muricata has a promising potential as a chemotherapeutic agent to cure cancer. From all these findings, not only the leaves, the whole A. muricata plant part proved to be a versatile anticancer agent. Referring to the main results of prospective in vitro and in vivo oncogenic investigations on various extracts of $A$. muricata leaves (Abdulwahab et al., 2018).

The growth of ovarian cancer both in vivo and in vitro can also be inhibited (Cletus et al., 2016). Annonacin, found in the leaves of Annona muricata, showed the effect of inducing $\mathrm{PaCa}-2$ cancer cell death in vivo (Yiallouris et al., 2018). Besides acetogenin, alkaloid compounds, (-)-coclaurine, (+)reticuline, argentinine, atherosperminine, and (+)-xylopine were isolated from the roots of Annona muricata Indonesia. (-)-coclaurine, (+)-reticuline was non-toxic to the human suspension cancer cell line (HL-60 leukemia cell) and two fibroblastic cell lines (A549 lung cancer cell and HepG2 liver cancer cell line).
(+)-Xylopine shows an IC50 of 20-80 M (Nugraha et al., 2019).

In addition to leaf extract, there are other parts of Annona Muricata can be used as an anticancer such as parts of the fruit, seeds, twigs and roots. Ethanol extracts from leaves, roots and twigs of Annona muricata have shown anti-proliferative effects on HL-60 cells with IC50 varying from 6-49 $\mathrm{g} / \mathrm{mL}$ (Pieme et al., 2014). In vivo acetogenin, Annomuricin E from Annona muricata leaves, was found to inhibit the growth of HT-29 cells. with an IC50 value of $1.62 \pm 0.24 \mathrm{~g} / \mathrm{mL}$ (Zorofchian, et al., 2015a). Leaf, seed and peel extract of Annona muricata was cytotoxic against CCRF-CEM leukemia cells with a value of $0.57 \pm 0.02 ; 0.36 \pm 0.03$ and $4.58 \pm$ $0.2 \mathrm{~g} / \mathrm{mL}$ (Kuete et al., 2016). Annona muricata fruit extract showed its toxic activity against breast cancer cells (MDA-MB-468) but did not show its toxicity against normal breast cells (MCF-10A) (Dai et al., 2011). Acetogenins, Muricin M, Muricin N and Muricenin, isolated from the fruit of Annona muricata, have been reported to be potent antiprostate cancer agents (Sun et al., 2016). The same thing also happened to HeLa cervical cancer cells given Methanol:dichloroethane extract (1:1) from Annona muricata fruit with

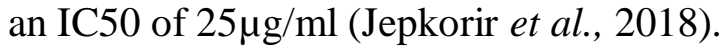

Annonaceous acetogenin was isolated from the seeds of Annona muricata: muricins AG, and known compounds: a mixture of muricatetrocin $\mathrm{A}$ and muricatetrocin $\mathrm{B}$, longifolicin, corossolin, and corossolone. These acetogenins exhibit significant selective in vitro cytotoxicity against the human hepatoma cell lines Hep G2 and 2,2,15 (Chang et al., 2001). Two years later, Annocatacin A and $\mathrm{B}$, isolated from methanol extracts of the seeds and leaves of Annona muricata, respectively, showed significant antiproliferative effects in vitro in human hepatoma cell lines, Hep G2 and Hep 2.2.15. 
Compounds 1 and 2 showed significant in vitro anti-proliferative effects in human hepatoma cell lines Hep G2 and Hep 2,2,15, but 2 were more selective against Hep G2 (Chang et al., 2003).

\section{Annona squamosal}

Squamocin-O1 and squamocin-O2 were reported from the methanol extract of Annona squamosa seeds. Cytotoxic activity of squamocin-O1 (1) and squamocin-O2 (2) against human K562 leukemia and HLE hepatoma cells. $\mathrm{n}(1: \mathrm{K} 562, \mathrm{IC} 50=4.0 \times 10-4$ $\mathrm{g} / \mathrm{ml}$; HLE, IC50=3.7 x 10-3 g/ml, 2: K562, IC50=4.3 x 10-4 g/ml; HLE, IC50=3.5 x 10-3 $\mathrm{g} / \mathrm{ml}$ (Araya et al., 2002) Squadiolins A and B showed high potency against human Hep G2 hepatoma cells and significant cytotoxic activity against human MDA-MB 231 breast cancer cells extracted from Annona squamosa seeds (Liaw et al., 2008). Further investigation, the bark extract protects the cell surface glycoconjugate for 7,12-dimethyl benz(a) anthracene (DMBA) induced hamster buccal sac carcinogenesis. Aqueous and ethanol extract can reduce the total number of tumors and normalize glycoconjugate levels in tumor carrier animals at doses of $500 \mathrm{mg} / \mathrm{kg}$ bw and $300 \mathrm{mg} / \mathrm{kg}$ bw (Suresh et al., 2010) Annona squamosa has shown significantly higher antitumor activity against MCF-7, HCT-116, KB-3- cells. 1, and HepG2.

This antitumor activity was further confirmed by in vivo studies conducted on mice with $\mathrm{H} 22 \mathrm{~d}$ hepatoma cells. An also against AD-5 tumors (Chen et al., 2011 and 2012, Yang et al., 2015). The mechanism that may be involved is the induction of apoptosis in tumor cells through the involvement of stress (De Pedro et al., 2013, Pandey, 2011, Pardhasaradhi et al., 2004 and 2005). Activity against lung and ovarian cancer cells of diterpene compounds isolated from bark (Sun et al., 2012).
Annosquacin-I, annosquatin-I, annosquatin-II, uvarigrandin A, bullatacin, squamostatin-A, and squamostatin-D were produced from the ethanol extract of Annona squamosal seeds. The five bioactive compounds had significant cytotoxic values for 5 types of human cancer cells, namely $1.2 \times 102-6.8 \times 101$ for A-549 (human lung cancer); $2.5 \times 102-1.5$ for HeLa (human cervical cancer); $4.3 \times 102$ $7.5 \times 101$ for MCF-7 (human breast cancer); $8.2 \times 103-8.3 \times 101$ for HepG2 ; $4.8 \times 103-$ $4.9 \times 101 \mathrm{~g} / \mathrm{ml}$ for SMMC-7721 (human hepatoma cancer) (chen2011), Annona squamosal leaf chloroform extract showed the strongest cytotoxic activity against MT-1 and MT-2 cells with values (EC 50) was > 100 $\mathrm{g} / \mathrm{Ml}$. Alkaloids were isolated as active compounds from Annona leaves. squamosa is and lanugiosine. (Nakano et al., 2013)

Squamocin-I (1), II (2) and III (3) and squamoxinone-D (4) were isolated from the seeds of Annona squamosa. Compounds 1-4 were tested for cytotoxicity against Hep G2, SMMC 7721, BEL 7402, BGC 803 and H460 human cancer cells. Compound 1 showed better cytotoxic activity and compound 3 showed selective cytotoxic activity against H460 with an IC50 value of $0.0492 \mathrm{~g} / \mathrm{ml}$. A year later Squamocin-IV (1), squamocin-V (2) and squamoxinone-E (3), along with seven other Annonaceous acetogenins were isolated. The new Annonaceous acetogenins 1-3 were tested for cytotoxicity against the human cancer cell lines Hep-G2, SMMC-7721, BEL7402, BGC-803 and H460. Compound 3 showed the best cytotoxic activity, with IC50 values of $0.103,0.687,4.19,0.43$ and 6.56 $\mathrm{g} / \mathrm{mL}$, for the tested cell lines. Meanwhile, Compound 1 showed selective cytotoxic activity against $\mathrm{H} 460$, with an IC50 value of $0.049 \mathrm{~g} / \mathrm{mL}$. The first mono-ACG (2) consisting of 38 carbons was discovered (Miao et al., 2015, Miao et al., 2016). In vivo, Squamocin and squamostatin (A, B, C, D and E) have important antitumor activity against 
AD-5 tumors (Bhattacharya and Chakraverty. 2016). Dieporeticenin B (1), squamocin P (2) and annosquatin III (3) were isolated from the seeds of Annona squamosa. This compound exhibited an inhibitory effect against three drug-resistant cancer cell lines. Compounds 2 and 3 showed selective cytotoxicity to SMMC 7721/T (IC50 0.435 and $1.79 \mathrm{M}$ ) and MCF7/ADR (IC50 values 3.34 and $4.04 \mathrm{M}$ ) (Ma et al., 2017)

\section{Annona reticulate}

The important antiproliferative activity of the ethanolic extract of Annona reticulata root in vitro against human cancer cell lines A-549, K-562, HeLa and MDA-MB could be attributed to the presence of acetogenins and alkaloids. Annona reticulate can be used as a chemopreventive agent in cancer therapy (Suresh et al., 2011).

The ethanolic extract of Annona reticulata root produces liriodenine (1) norushinsunine (2), reticuline (3) and neoannonine (4). Found an inhibitory effect against human lung carcinoma (A-549), chronic myelogenous leukemia in human bone marrow (K-562), cervical carcinoma (HeLa) and human mammary gland adenocarcinoma tumors (MDA-MB). Neoannoninacetogenin gave the strongest cytotoxicity in each cell tested IC50 $=5.8-6.9 \mathrm{~g} / \mathrm{ml}$. (Suresh et al., 2012).

\section{Strongest activity against MT-1 and M.cells}

T-2 was shown from the chloroform extract of Annona reticulata leaves while the bark showed moderate activity. The cytotoxicity activity of Annona reticulata extract has a value (EC 50) is > $100 \mathrm{~g} / \mathrm{mL}$. Two alkaloids isolated as active compounds from the leaves of Annona reticulata are liriodenine (1), lysicamina (2), and lanugiosine (3) (Nakano et al., 2013).

Long ago Annonacin from Annona reticulata seeds caused cell death of ovarian cancer (SKOV3 and PA-1), cervical cancer (HeLa and HeLa S3), breast cancer (MCF7), bladder cancer (T-24) and skin cancer (BCC-1).) with each IC50 value $=0.452 ; 0.411 ; 0.219 ; 4.26$; 4.33; 0.324 and $0.427 \mathrm{~g} / \mathrm{mL}$ (yuan SSF et al., 2002). This effect may be attributed to the presence of acetogenins and alkaloids

Annonacin, a monotetrahydrofuranacetogenin was isolated from the seeds of Annona reticulata and showed it causes significant cell death in various cancer cells and this compound has the potential to be a promising compound.

\section{Annona cherimola}

Annona ceousacetogenins isolated from the extract of Annona cherimolia seeds were filtered to obtain annomolin (1) and annocherimolin (2). Annomolin showed strong cytotoxicity against breast (MCF-7), colon (HT-29) and prostate (PC-3) cell lines. demonstrated cytotoxic selectivity for human prostate tumor cell line (PC-3), with a potency more than 10,000 times that of adriamycin. annocherimolin (2) showed an approximately 10,000-fold cytotoxic potential of adriamycin in breast (MCF-7) and colon (HT-29) cancer cell lines. Blockage of mitochondrial complex I (NADH-ubiquinone oxidoreductase) and inhibition of NADH oxidase may be the mechanisms responsible for the cytotoxic activity of this acetogenin (Kim et al., 2001) 
Table.1 Secondary metabolites in Annona cherimola, Annona muricata, Annona reticulata and Annona Squamosa

\begin{tabular}{|c|c|c|c|c|}
\hline Species & Active Compound & $\begin{array}{l}\text { Compound } \\
\text { Group }\end{array}$ & Tested cancer cells & Reference \\
\hline \multirow[t]{10}{*}{$\begin{array}{l}\text { Annona } \\
\text { cherimola }\end{array}$} & $\begin{array}{l}\text { Leaves :annocherine C (1), } \\
\text { liriodenine (2), oxoxylopine } \\
\text { (3), oxonantenine (4), (-)- } \\
\text { asimilobine (5), (-)-xylopine (6) } \\
\text { and (-)-anolobine (7) }\end{array}$ & ALK & - & $\begin{array}{l}\text { Chen \& } \\
\text { Wu, } 2001\end{array}$ \\
\hline & $\begin{array}{c}\text { Leaves : anonaine, liriodenine, } \\
\text { dannornuciferine }\end{array}$ & & - & $\begin{array}{l}\text { Martínez- } \\
\text { Vázquez et } \\
\text { al., } 2012\end{array}$ \\
\hline & $\begin{array}{l}\text { Stem : Annocherine A dan B, } \\
\text { Artabonatine } \mathrm{B} \text {, Cherianoine, } \\
\text { romucosine } \mathrm{H}\end{array}$ & ALK & - & $\begin{array}{l}\text { Chen et al } \\
2001\end{array}$ \\
\hline & $\begin{array}{l}\text { Fruit : } \alpha \text {-pinene, } \beta \text {-pinene, } \\
\text { limonene, bornyl acetate and } \\
\text { germacrene D. }\end{array}$ & & - & $\begin{array}{l}\text { Pino et al. } \\
\quad 2001\end{array}$ \\
\hline & $\begin{array}{c}\text { Seed : annomolin (1) } \\
\text { danannocherimolin (2) }\end{array}$ & ACT & $\begin{array}{c}\text { Annomolin was more } \\
\text { cytotoxic to PC-3 cells } \\
\text { and Annocherimolin was } \\
\text { more cytotoxic to MCF-7 } \\
\text { and HT29 cells. }\end{array}$ & $\begin{array}{l}\text { Kim et al. } \\
\quad 2001\end{array}$ \\
\hline & $\begin{array}{c}\text { Seed : annomocherin (1), } \\
\text { annonacin (2) danannomontacin } \\
\text { (3) }\end{array}$ & ACT & $\begin{array}{l}\text { Compound } 1 \text { showed } \\
\text { strong and selective } \\
\text { cytotoxicity against MCF- } \\
7 \text { and A-498 cells. }\end{array}$ & $\begin{array}{l}\text { Kimet al. } \\
\quad 2001\end{array}$ \\
\hline & Seed : annomolon A dan B & ACT & $\begin{array}{l}\text { Both compounds are more } \\
\text { toxic to MIA PaCa- } 2 \text { cells }\end{array}$ & $\begin{array}{l}\text { Son et al } \\
2003\end{array}$ \\
\hline & Seed: asimicin, tucumanin & ACT & - & $\begin{array}{l}\text { Barrachina } \\
\text { et al. } 2004\end{array}$ \\
\hline & Seed : cherimolacyclopeptide C & CYP & - & $\begin{array}{l}\text { Wele } \text { et al } \\
2004\end{array}$ \\
\hline & $\begin{array}{l}\text { Root : corytenchine (1) and } \\
\text { isocoreximine (2) }\end{array}$ & & $\begin{array}{l}\text { isocoreximine showed } \\
\text { more cytotoxic activity } \\
\text { against K-562, U-251, } \\
\text { PC-3, HCT-15, and MCF- } \\
7 \text { thanncorytenchine }\end{array}$ & $\begin{array}{l}\text { Martinez- } \\
\text { Vazquez, } \\
\text { M } \\
\text { dkk.2005 }\end{array}$ \\
\hline \multirow[t]{2}{*}{$\begin{array}{l}\text { Annona } \\
\text { muricata }\end{array}$} & $\begin{array}{c}\text { Leaves : Anonaine, } \\
\text { Benzyltetrahydroisoquinoline, } \\
\text { coclaurine, isolaureline, } \\
\text { xylopine }\end{array}$ & ALK & - & $\begin{array}{l}\text { Fofana et al } \\
\quad 2011\end{array}$ \\
\hline & Leaves : (R)-4'-O- & ALK & Neurotoxic to SH-SY5Y & Matsushige \\
\hline
\end{tabular}




\begin{tabular}{|c|c|c|c|}
\hline $\begin{array}{c}\text { methylcoclaurine, }(\mathrm{R})- \\
\text { anonaine, }:(\mathrm{R})-\mathrm{O}-\mathrm{O}- \\
\text { dimethylcoclaurine, }(\mathrm{S})- \\
\text { norcorydine, annonamine }\end{array}$ & & cells & et al. 2012 \\
\hline $\begin{array}{l}\text { Leaves : Argentinine, } \\
\text { Catechine, Chlorogenic acid, } \\
\text { Epicatechine Gallic acid, } \\
\text { Kaempferol, Kaempferol 3-O- } \\
\text { rutinoside, Quercetin 3-O- } \\
\text { glucoside, Quercetin 3-O- } \\
\text { neohispredoside, Quercetin 3- } \\
\text { O-robinoside, Quercetin 3-O- } \\
\text { rutinoside }\end{array}$ & FLA & 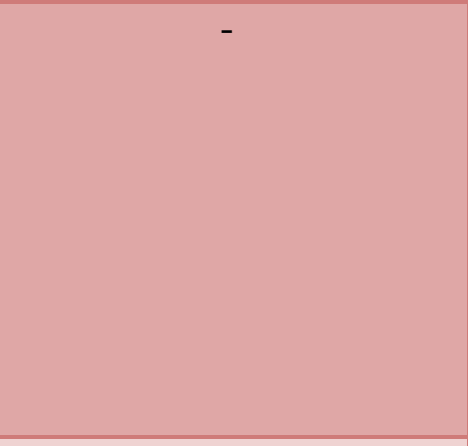 & $\begin{array}{l}\text { Nawwar } \\
\text { et.al. } 2012\end{array}$ \\
\hline $\begin{array}{l}\text { Leaves : Annoionol A dan B, } \\
\text { annoionosidedanannoionol C }\end{array}$ & MSG & $\begin{array}{l}\text { inhibition of tumor cell } \\
\text { growth towards A549 and } \\
\text { SBC-3 }\end{array}$ & $\begin{array}{l}\text { Matsushige } \\
\text { et al. } 2012\end{array}$ \\
\hline $\begin{array}{l}\text { Leaves, pericarp, Root, dan } \\
\text { Seed : annonacin }\end{array}$ & ACT & - & $\begin{array}{l}\text { Luna et al. } \\
\text { 2006, } \\
\text { Jaramilo et } \\
\text { al. } 2000 \text {, } \\
\text { Champy et } \\
\text { al. } 2004\end{array}$ \\
\hline $\begin{array}{l}\text { Leaves And Seed: annocatacin } \\
\text { A dan B }\end{array}$ & $\mathrm{ACT}$ & $\begin{array}{c}\text { Showed significant } \\
\text { cytotoxic activity against } \\
\text { Hep G2 and Hep 2.2.15 } \\
\text { cells }\end{array}$ & $\begin{array}{l}\text { Chang et } \\
\text { al. } 2003\end{array}$ \\
\hline $\begin{array}{l}\text { Leaves and Seed : muricin } \mathrm{H} \text {, } \\
\text { muricin I, cisannomontacin, } \\
\text { annocatalin, cis-corossolone }\end{array}$ & ACT & $\begin{array}{c}\text { Showed significant } \\
\text { cytotoxic activity against } \\
\text { Hep G2 and Hep 2.2.15 } \\
\text { cells }\end{array}$ & $\begin{array}{l}\text { Liaw et al. } \\
\quad 2002\end{array}$ \\
\hline $\begin{array}{l}\text { Leaves And Seed : } \\
\text { annonacinone }\end{array}$ & $\mathrm{ACT}$ & - & $\begin{array}{l}\text { Liaw et al. } \\
\text { 2002, Vila- } \\
\text { Nova et al. } \\
\quad 2011\end{array}$ \\
\hline Leaves and Seed: corossolone & ACT & 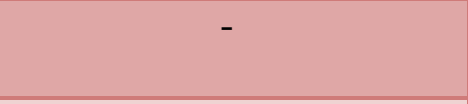 & $\begin{array}{l}\text { Vila-Nova } \\
\text { et al. } 2011\end{array}$ \\
\hline Leaves : Annomuricin E & & $\begin{array}{l}\text { The cytotoxic effect of } \\
\text { annomuricin E inhibited } \\
\text { the growth of HT- } 29 \text { cells } \\
\text { with an IC50 value of } \\
1.62 \pm 0.24 \mathrm{~g} / \mathrm{ml}\end{array}$ & $\begin{array}{l}\text { Zorofchian } \\
\text { et al. } 2015\end{array}$ \\
\hline $\begin{array}{l}\text { Leaves And Seed: } \\
\text { goniothalamicin, isoannonacin }\end{array}$ & $\mathrm{ACT}$ & - & $\begin{array}{l}\text { Luna et al. } \\
\quad 2006\end{array}$ \\
\hline $\begin{array}{l}\text { Stem Bark : Muricins A-G (1- } \\
\text { 7) muricatetrocin A (8) } \\
\text { danmuricatetrocin B (9), }\end{array}$ & $\mathrm{ACT}$ & $\begin{array}{l}\text { Showed significant } \\
\text { cytotoxic activity against } \\
\text { Hep G2 and Hep 2.2.15 }\end{array}$ & $\begin{array}{l}\text { Chang and } \\
\text { Wu. } 2001\end{array}$ \\
\hline
\end{tabular}




\begin{tabular}{|c|c|c|c|}
\hline $\begin{array}{l}\text { longifolicin (10), corossolin } \\
\text { (11), dancorossolone (12) }\end{array}$ & & cells & \\
\hline $\begin{array}{l}\text { Fruit : annoreticuin-9-one (1) } \\
\text { cis-annoreticuin (2) and } \\
\text { sabadelin (3) }\end{array}$ & ACT & $\begin{array}{c}\text { Compound } 1 \text { shows its } \\
\text { cytotoxic activity against } \\
\text { cells PACA-2), PC- } 3 \text { and } \\
\text { A-549, while } 2 \text { cells Hep } \\
\text { G2 }\end{array}$ & $\begin{array}{l}\text { Ragasa et } \\
\text { al } 2012\end{array}$ \\
\hline $\begin{array}{l}\text { Fruit : Epomuricenins-A dan B; } \\
\text { Epomurinins-A dan B; } \\
\text { Epomusenins A dan B }\end{array}$ & ACT & - & $\begin{array}{l}\text { Molet } \text { et al } \\
\quad 2009\end{array}$ \\
\hline Fruit : Muricin J, K dan L & ACT & $\begin{array}{l}\text { Antiproliferative } \\
\text { properties against PC-3 } \\
\text { cells }\end{array}$ & $\begin{array}{l}\text { Sun et al. } \\
\quad 2014\end{array}$ \\
\hline $\begin{array}{c}\text { Fruit: muricin } \mathrm{M} \text { dan } \mathrm{N}, \\
\text { muricenin }\end{array}$ & ACT & $\begin{array}{l}\text { showed stronger anti- } \\
\text { proliferative activity } \\
\text { against human prostate } \\
\text { cancer cells PC-3 }\end{array}$ & $\begin{array}{l}\text { Sun et al. } \\
\quad 2016\end{array}$ \\
\hline Fruit dan Root : Sabadelin & ACT & - & $\begin{array}{c}\text { Ragasa } \text { et } \\
\text { al } 2012\end{array}$ \\
\hline Pericarp : Annomuricin A & ACT & - & $\begin{array}{l}\text { Jaramilo et } \\
\text { al. } 2000\end{array}$ \\
\hline Pericarp danbiji : Annonacin A & ACT & - & $\begin{array}{l}\text { Jaramilo et } \\
\text { al. } 2000\end{array}$ \\
\hline Seed : Cohibins C dan D & $\mathrm{ACT}$ & - & $\begin{array}{l}\text { Gleye et al. } \\
2000\end{array}$ \\
\hline $\begin{array}{c}\text { Seed : muricins A-G (1-7), } \\
\text { muricatetrocin A (8) } \\
\text { danmuricatetrocin B (9), } \\
\text { longifolicin (10), corossolin } \\
\text { (11), dancorossolone (12) }\end{array}$ & ACT & $\begin{array}{c}\text { These acetogenins exhibit } \\
\text { significant cytotoxicity } \\
\text { that are selective against } \\
\text { Hep G2 and Hep } 2,2,15 \\
\text { cells in vitro. }\end{array}$ & $\begin{array}{l}\text { Chang \& } \\
\text { Wu. } 2001\end{array}$ \\
\hline $\begin{array}{c}\text { Seed : 2,4-cis- } \\
\text { Gigantetrocinone, 2,4-trans- } \\
\text { gigantetrocinone, 2,4-trans- } \\
\text { isoaiinonacin, 2,4-trans- } \\
\text { Isoannonacin- 10-one, } \\
\text { Annomontacin, Gigantetrocin- } \\
\text { A dan B Gigantetronenin, } \\
\text { Muricatenol }\end{array}$ & ACT & - & $\begin{array}{l}\text { Li et al. } \\
2001\end{array}$ \\
\hline Seed : Annomuricatin C & & & $\begin{array}{l}\text { Wele } \text { et al. } \\
\quad 2004\end{array}$ \\
\hline Seed : cherimolacyclopeptide C & & $\begin{array}{l}\text { showed significant in } \\
\text { vitro cytotoxic activity } \\
\text { against } \\
\text { KB cell }\end{array}$ & $\begin{array}{l}\text { Wele et al. } \\
\quad 2004\end{array}$ \\
\hline Root : Neoannonin-B & ACT & - & Gleye $e t$ \\
\hline
\end{tabular}




\begin{tabular}{|c|c|c|c|c|}
\hline & & & & al., 2001 \\
\hline \multirow[t]{5}{*}{$\begin{array}{l}\text { Annona } \\
\text { reticula }\end{array}$} & $\begin{array}{l}\text { Leaves : (E,E)-farnesyl acetate, } \\
\text { ar-turmerone, benzyl benzoate } \\
\text { and } \gamma \text {-terpinene }\end{array}$ & ESO & - & $\begin{array}{l}\text { Ogunwande } \\
\text { et al. } 2006\end{array}$ \\
\hline & $\begin{array}{l}\text { Stem Bark : Kaur-16-en-19-oic } \\
\text { acid, kopaena }\end{array}$ & & & $\begin{array}{l}\text { Chavan et } \\
\text { al., } 2012\end{array}$ \\
\hline & Seed : Annonacin & ACT & $\begin{array}{l}\text { annonacin causes } \\
\text { significant cell death }\end{array}$ & $\begin{array}{l}\text { Yuan et al. } \\
\quad 2003\end{array}$ \\
\hline & $\begin{array}{l}\text { Seed : cycloreticulin A } \\
\text { dancycloreticulin B }\end{array}$ & & - & $\begin{array}{l}\text {. Wele } e t \\
\text { al., } 2008\end{array}$ \\
\hline & Seed : squamocin & & $\begin{array}{c}\text { Cytotoxic against KB 3-1 } \\
\text { cells in vitro }\end{array}$ & $\begin{array}{l}\text { Duval et al. } \\
\quad 2005\end{array}$ \\
\hline \multirow[t]{7}{*}{$\begin{array}{l}\text { Annona } \\
\text { squamosa }\end{array}$} & $\begin{array}{l}\text { Leaves : Quercetin-3-O- } \\
\text { glucoside }\end{array}$ & FLA & - & $\begin{array}{c}\text { Panda } \\
\& \text { Kar, } 2007\end{array}$ \\
\hline & Leaves : O-methylarmepavine & ALK & - & $\begin{array}{l}\text { Vila-Nova } \\
\text { et al. } 2011\end{array}$ \\
\hline & $\begin{array}{c}\text { Leaves : Bicyclogermacrene, } \\
\text { (E)-Caryophyllene, Germacrene } \\
\text { D }\end{array}$ & ESO & - & $\begin{array}{l}\text { Meira et al. } \\
\quad 2014\end{array}$ \\
\hline & Leaves : (-)- Anonaine & ALK & - & $\begin{array}{l}\text { Porwal\& } \\
\text { Kumar, } \\
2015\end{array}$ \\
\hline & $\begin{array}{l}\text { Fruit : } \alpha \text {-pinene, Limonene, } \\
\text { Sabinene }\end{array}$ & ESO & - & $\begin{array}{l}\text { Andrade } e t \\
\text { al.,2001 }\end{array}$ \\
\hline & $\begin{array}{c}\text { Seed : Annosquamins A, } \\
\text { Annosquamins B, } \\
\text { Annosquamins C }\end{array}$ & ACT & & $\begin{array}{l}\text { Chen et al., } \\
\quad 2012\end{array}$ \\
\hline & 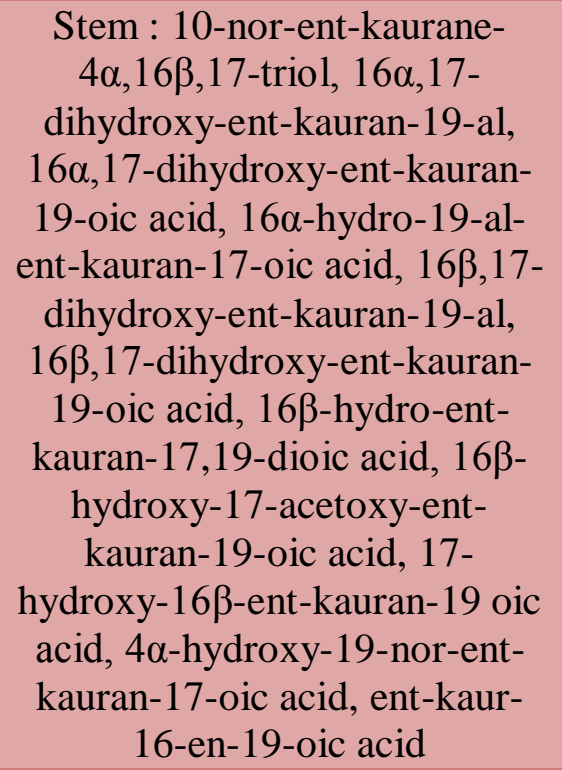 & ALK & & $\begin{array}{l}\text { Yang et al. } \\
\quad(2004)\end{array}$ \\
\hline
\end{tabular}


Table. 2 The structure of bioactive compounds that have anticancer activity

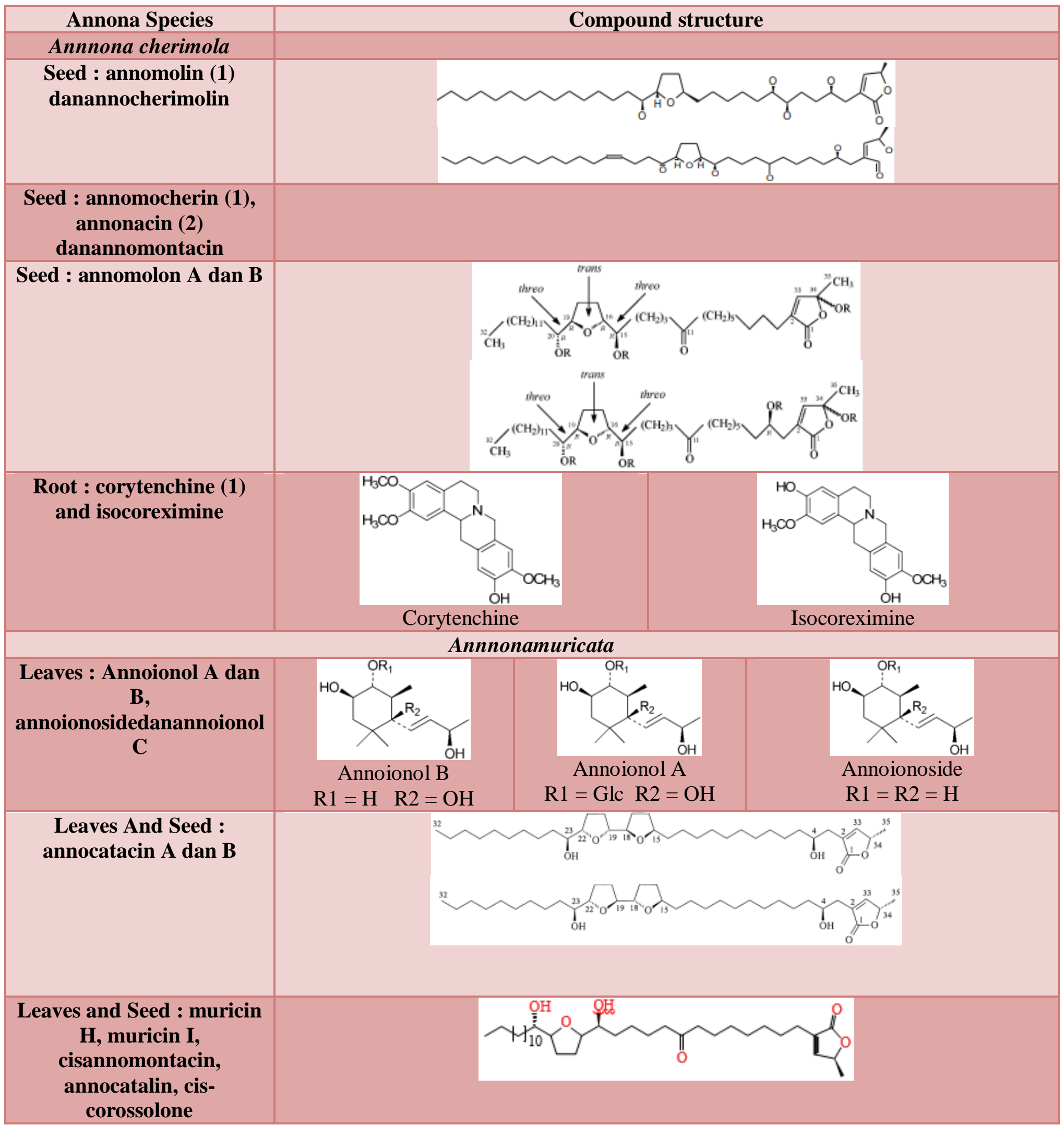




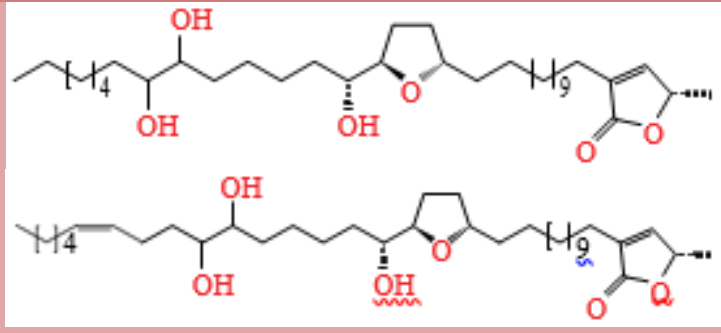

\section{Leaves : Annomuricin E \\ Seed : \\ cherimolacyclopeptide $\mathbf{C}$}

annoreticuin (2)

sabadelin (3)
Fruit :
Muricin J,

sabadelin (3)
Fruit :
Muricin J,

sabadelin (3)
Fruit :
Muricin J,

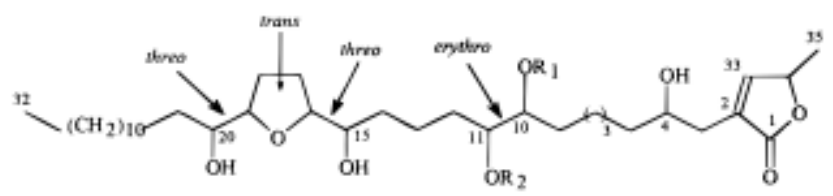

annoreticuin-9-one (1)

Fruit :

Muricin K
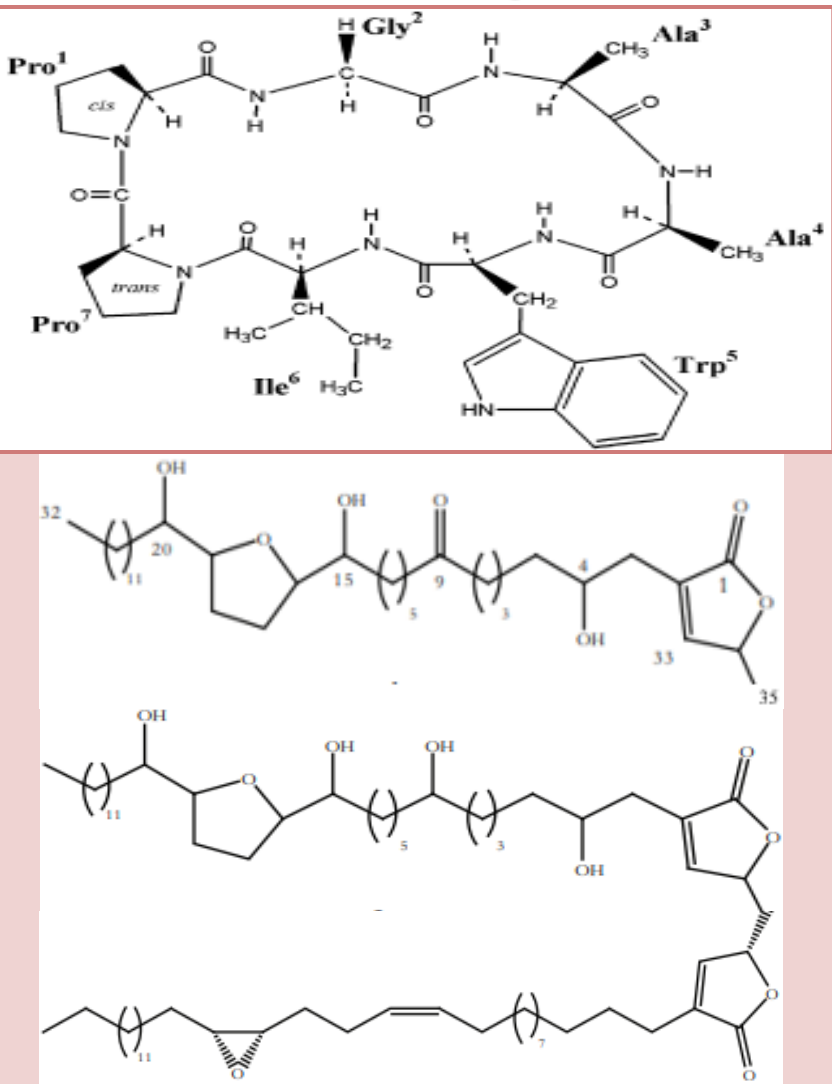

Muricin L

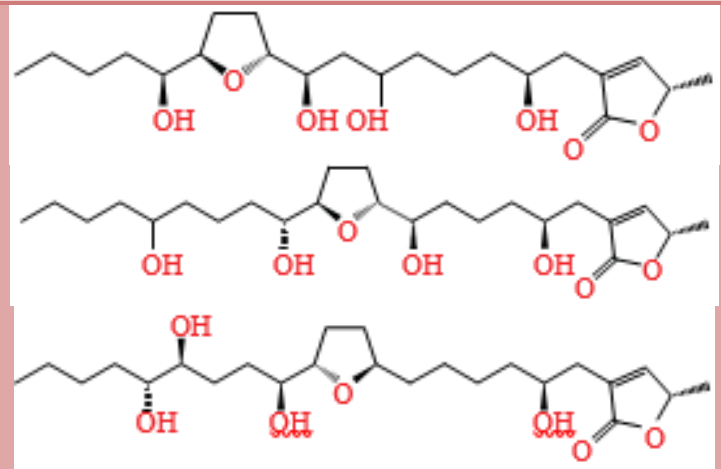




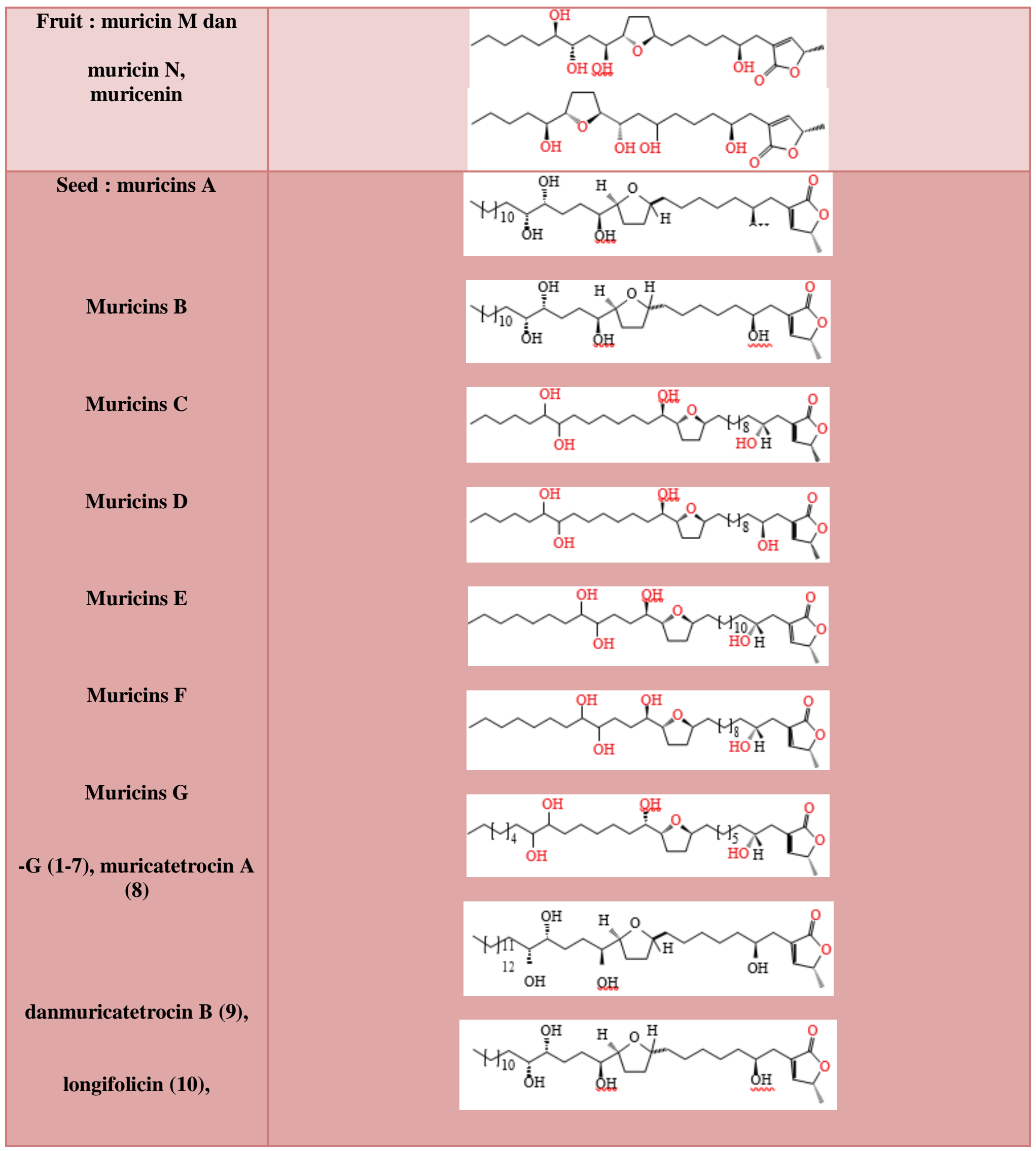




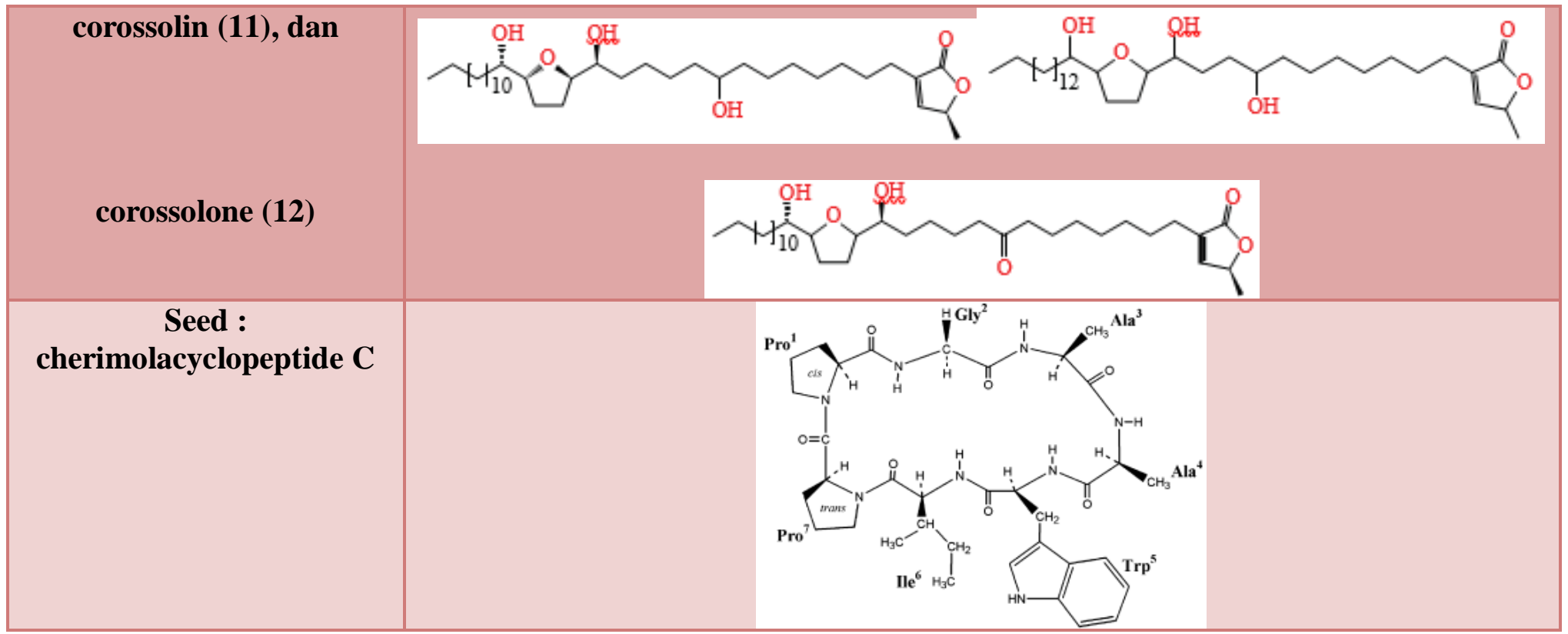

Isocoreximine alkaloid isolated from Annona cherimola, at a concentration of $50 \mathrm{~g} / \mathrm{mL}$ showed cytotoxicity to K-562, U-251, PC-3, HCT-15, and MCF-7 with \% inhibition of cell viability $94.15 \%, 65$, respectively..23\%, $78.71 \%, 63.05 \%$, and $85.76 \%$. Isocoreximine showed cytotoxic activity in vitro against $\mathrm{K}$ 562, U-251, PC-3, HCT-15, and MCF-7 with $\%$ inhibition of cell viability $94.15 \%, 65.23 \%$, $78.71 \%$, respectively. $63.05 \%$, and $85.76 \%$ (Martinez-Vazquez, et al., 2005).

Annomolon A, annomolon B, and 34-epi annomolon A,B in Annona cherimola showed selective inhibition of mitochondrial complex I and specificity against different tumor lines of cells (De Pedro et al., 2013). The essential oil and ethanolic extract obtained from Annona cherimola leaves were screened for antitumor activity against cancer (MCF-7), colon cancer (CACO-2) and liver cancer cell lines (HEPG-2). $0.03 \%$ essential oil was obtained which mainly contained sesquiterpenes and monoterpenes. Most included -elemene $(25.02 \%)$, germacrene-D $(17.71 \%)$, and -caryophyllene $(9.50 \%)$. The ethanol extract showed significant cytotoxic activity on MCF-7, CACO-2 and HEPG-2 with IC50 of $3.43,2.97$ and $3.73 \mathrm{~g} / \mathrm{ml}$, respectively. The study concluded that the essential oil of the ethanolic extract had strong cytotoxic activity on all tested cell lines showing promising antitumor activity of Annona cherimola (Elhawary et al., 2013).

\section{Relationship of Structure with Anticancer Properties}

The presence of part of the THF and/or THP ring in the compound chain, with the presence of a THF and/or THP ring in the compound chain so that it can have a V-type shape. The molecular length of the compound (33-38), the width of the three-dimensional structure of the compound, all of which are very important for the activity of inhibiting the growth of cancer cells. In addition, the position of the $\mathrm{OH}$ group in the compound affects the activity of inhibiting the growth of cancer cells. In this report, specifically mentions, compound 5 (pyranicin) showed the strongest inhibition of the acetogenins tested, affecting not only cell proliferation but also apoptosis induction.

Therefore, compound 5 is the main compound of cancer chemotherapeutic agents that have the potential to be developed (mitsui et al., 2009). 
The large number of hydroxyl groups supported by the hydroxyl position flanking the -lactone ring and the stereochemical arrangement of the THF ring determine the effectiveness of cytotoxic activity. (liaw et al., 2008)

Bioactivity data showed that the annonaceousbistetrahydrofuranacetogenins adjacent to nosquacin-I, uvarigrandin $\mathrm{A}$, and bullatacin were more cytotoxic than the nonaceousbistetrahydrofuranacetogeninssqua mostatin-A, squamostatin-D, annosquatin-I, and annosquatin-II.

The free $\mathrm{OH}$ at $\mathrm{C}-4$ appears to increase the cytotoxicity of acetogenin. For example, roundacin and annosquatin-II are more active than uvarigrandin $\mathrm{A}$ and annosquatin-I. The nonadjacent

tetrahydroxylatedbistetrahydrofuranAnnonace ous acetogeninsquamostatin- $\mathrm{A}$ is less cytotoxic than trihydroxylatedsquamostatin-D. (Chen Y. et al., 2011)

The adjacent ACG bis-THF exhibited higher antitumor activity and toxicity than the nonadjacent mono-THF and ACG bis-THF in vivo. (Chen Y et al., 2012) Acetogenins with hydroxyl located at C 16, 19 and 24 have strong cytotoxicity against A-549 cells. The number of hydroxyl can determine the cytotoxic properties supported by the presence of adjacent bis-non-ACG THF. The stereochemical arrangement of the THF ring is important for ACG bioactivity, threo/trans/erythro being more active than threo/trans/threo. (Yuan F et al., 2015)

The high cytotoxic activity against H460 may be due to the presence of a hydroxyl group at the tail of the ACG carbon chain. (Mio et al., 2015).

There are many metabolites found in Annona plants, especially Annona cherimola, Annona muricata, Annona retukula and Annona squamosal in every part of the plant. Most of the secondary metabolites that have anticancer activity are found in the leaves, seeds and fruit.

Acetogenen compounds (ACT), alkaloids (ALK) and flavonoids (FLA) contained in the Annona plant have many anticancer roles. Anticancer activity has been investigated is influenced by the structure of these bioactive compounds, for example for ACT due to the THF ring (tetrahydrofuran) as discussed in point 5

\section{Acknowledgements}

The author would like to thank the ministry of industry for providing the master's degree scholarship. Supervising Lecturer for Master's Thesis Dr. Afrizal and Dr. Mai Efdi. Family and friends who have encouraged me.

\section{References}

A. Jayaprakash. Phytochemicals, Antimicrobial and Antioxidant Properties of Annona reticulata Linn. Journal of Academia and Industrial Research (JAIR) Volume 6, Issue 6, November 2017. ISSN: 2278-5213.

Abdul Wahab, S. M., Jantan, I., Haque, M. A., \& Arshad, L. (2018). Exploring the Leaves of Annona muricata L. as a Source of Potential Anti-inflammatory and Anticancer Agents. Frontiers in Pharmacology, 9.

Adewole S O and Ojewole J A (2008). Protective effects of Annona muricata Linn. (Annonaceae) leaf aqueous extract on serum lipid profiles and oxidative stress in hepatocytes of streptozotocin-treated diabetic rats. Afr. J. Tradit. Complement Altern. Med., 6: $30-41$

Agrawal, Mona, Agrawal Yogesh, Itankar Prakash, Patil Arun, Vyas Jayshree, Kelkar Amruta. Phytochemical and HPTLC Studies of Various Extracts of Annona squamosa (Annonaceae). International Journal of PharmTech Research, 4(1), 2012, 364-368. 
Alassane Wele, Idrissa Ndoye and Mamadou Badiane. Fatty Acid and Essential Oil Compositions of The Seed Oil of five Annona species. Nig. Journal of Natural Products and Medicines, 4, 2004, 62-65

Araya, H., Sahai, M., Singh, S., Singh, A. K., Yoshida, M., Hara, N., \& Fujimoto, Y. (2002). Squamocin-O 1 and squamocin-O 2, new adjacent bis-tetrahydrofuran acetogenins from the seeds of Annona squamosa. Phytochemistry, 61(8), 999-1004.

Andrade E H A, Zoghbi Md G B, Maia J G S, Fabricius H, Marx F. 2001. Chemical characterization of the fruit of Annona squamosa L. occurring in the amazon. J Food Compost Anal 14: 227-32. doi: 10.1006/jfca.2000.0968

Araya H, Sahai M, Singh S et al., (2002) Squamocin-O-1 and squamocin-O-2, new adjacent bistetrahydrofuran acetogenins from the seeds of Annona squamosa. Phytochemistry 61:999-1004

Asare, G. A.; Afriyie, D.; Ngala, R. A.; Abutiate, H.; Doku, D.; Mahmood, S. A.; Rahman, H. Antiproliferative activity of aqueous leaf extract of Annona muricata L. on the prostate, BPH-1 cells, and some target genes. Integr. Cancer Ther. 2015, 14, 65-74

Ashok kumar J, Rekha T, Shyamala Devi S, Kannan M, Jaswanth A, Gopal V. Insecticidal Activity of Ethanolic Extract of Leaves of Annona squamosa, J. Chem. Pharm. Res., 2(5), 2010, 177-180.

Barrachina I, Neske A, Granell S, Bermejo A, Chahboune N, El Aouad N. 2004. Tucumanin, a beta-hydroxy-gamma-lactone bistetrahydrofuranic acetogenin from Annona cherimolia, is a potent inhibitor of mitochondrial complex I. Planta Med 70: 8668. doi: $10.1055 / \mathrm{s}-2004-827237$

Badrie, N.; Schauss, A. G. Soursop (Annona muricata L.): Composition, nutritional value, medicinal uses, and toxicology. In Bioactive Foods in Promoting Health; Watson, R. R., Preedy, V. R., Eds.; Elsevier Inc.: London, UK, 2010

Barbalho, S.; de Goulart, R.; Vasques FarinazziMachado, F.; da Soares de Souza, M.; Santos Bueno, P.; Guiguer, E.; Araujo, A.; Groppo, M. Annona sp: Plants with Multiple Applications as Alternative Medicine - A
Review. Curr. Bioact. Compd. 2012, 8, 277286.

Champy, P., Guérineau, V., and Laprévote, O. (2009). MALDI-TOF MS profiling of annonaceous acetogenins in Annona muricata products for human consumption. Molecules 14, 5235-5246. doi: 10.3390/molecules14125235

Chang F R, Liaw C C, Lin C Y, Chou C J, Chiu H F, Wu Y C. 2003. New adjacent bistetrahydrofuran Annonaceous acetogenins from Annona muricata. Planta Med 69(3): 24146. doi: $10.1055 / \mathrm{s}-2003-38485$

Chang and Y. C. Wu, "Novel cytotoxic annonaceous acetogenins from Annona muricata," Journal of Natural Products, vol. 64, no. 7, pp. 925-931, 2001

Chavan M J, Kolhe D R, Wakte P S, Shinde D B. Analgesic and antiinflammatory activity of Kaur-16-en-19-oic acid from Annona reticulata L. Bark. Phytother Res. 2012;26:273-276

Chavan M J, Wakte P S, Shinde D B. Analgesic and anti-inflammatory activities of the sesquiterpene fraction from Annona reticulata L. Bark. Nat Prod Res. 2012;26:1515-1518

Chen C Y, Chang F R, Pan W B, Wu Y C. 2001. Four alkaloids from Annona cherimola. Phytochem 56(7): 753-7. doi: 10.1016/s00319422(00)00486-6

Chen Y, Chen J W, Li X. 2012. Monotetrahydrofuran Annonaceous acetogenins from the seeds of Annona squamosa. Phytochem Lett 5(1): 33-6. doi: 10.1016/j.phytol.2011.08.015

Chen, Y., Xu, S., Chen, J., Wang, Y., Xu, H., Fan, N., \& Li, X. (2012). Anti-tumor activity of Annona squamosa seeds extract containing annonaceous acetogenin compounds. Journal of Ethnopharmacology, 142(2), 462-466.

Chen, Y., Chen, J., \& Li, X. (2011). Cytotoxic Bistetrahydrofuran Annonaceous Acetogenins from the Seeds of Annona squamosa. Journal of Natural Products, 74(11), 2477-2481.

Coria-Téllez, Ana V.; Montalvo-Gónzalez, Efigenia; Yahia, Elhadi M.; Obledo-Vázquez, Eva N. (2016). Annona muricata: A comprehensive review on its traditional medicinal uses, phytochemicals, pharmacological activities, mechanisms of action and toxicity. Arabian Journal of 
Chemistry,

S1878535216000058.doi:10.1016/j.arabjc.2016 .01 .004

Dai, S Y. Hogan, E. M. Schmelz, Y. H. Ju, C. Canning, and K. Zhou, "Selective growth inhibition of human breast cancer cells by graviola fruit extract in vitro and in vivo involving downregulation of EGFR expression," Nutrition and Cancer, vol. 63, no. 5, pp. 795-801, 2011. In vitro

Duval R A, Duret P, Lewin G, Peris E, Hocquemiller R. Semisynthesis and biollogical activity aminoacyl trimesters of squamocin, an annonaceous acetogenin. Bioorg Med Chem. 2005;13:3773-3781

Ezirim A U, Okochi V I, James A B, Adebeshi O A, Ogunnowo S and Odeghe O (2013). Induction of apoptosis in myelogenous leukemic k562 cells by ethanolic leaf extract of Annona muricata. Ind. J. Drugs and Dis., 2: 241-247

Fofana, S., Ziyaev, R., Abdusamatov, A., and Zakirov, S. K. (2011). Alkaloids from Annona muricata leaves. Chem. Nat. Compd. 47, 321321. doi: 10.1007/s10600-011-9921-5.

Fofana, S., Keita, A., Balde, S., Ziyaev, R., and Aripova, S. (2012). Alkaloids from leaves of Annona muricata. Chem. Nat. Comp. 48, 714714. doi: 10.1007/s10600-012-0363-5

Gavamukulya, Y., Abou-Elella, F., Wamunyokoli, F., and AEl-Shemy, H. (2014). Phytochemical screening, anti-oxidant activity and in vitro anticancer potential of ethanolic and water leaves extracts of Annona muricata (Graviola). Asian Pac. J. Trop. Med. 7, S355-S363. doi: 10.1016/S1995-7645(14)60258-3

Gleye C, Raynaud S, Fourneau C, Laurens A, Lapre'vote O, Serani L. 2000. Cohibins C and $\mathrm{D}$, two important metabolites in the biogenesis of acetogenins from Annona muricata and Annona nutans. J Nat Prod 63(9): 1192-6. doi: 10.1021/np000061a

Gleye C, Akendengue B, Laurens A, Hocquemiller R. 2001. Coronin from roots of Annona muricata, a putative intermediate in acetogenin biosynthesis (1). Planta Med 67(6): 570-2. doi: 10.1055/s-2001-16481

Hansra D, Silva O, Mehta A and Ahn E (2014). Patient with Metastatic Breast Cancer Achieves Stable Disease for 5 Years on Graviola and Xeloda after Progressing on
Multiple Lines of Therapy. Adv. Breast Cancer Res., 3: 84-87

Hatano H, Aiyama R, Matsumoto S, Nishisaka F, Nagaoka M, Kimura K, Makino T, Shishido Y, Hashimoto S. Cytotoxic constituents in the branches of Annona squamosa grown in Phillipines; Annual Report of the Yakult Institute for Microbiological Research, 22, 2002, 5-9

Haykal, T., Peter Nasr, Mohammad H. Hodroj, Robin I. Taleb, Rita Sarkis, Marvy Nadine El. Moujabber and Sandra Riz. Annona cherimola Seed Extract Activates Extrinsic and Intrinsic Apoptotic Pathways in Leukemic Cells. Toxins 2019, 11, 506; doi:10.3390/toxins11090506.

Henry Nettey, Ukwubile Cletus Anes. Antimicrobial activity and Characterization of Annona muricata leaf loaded chitosan nanoparticle against cancer associated microbes. International Journal of Research Studies in Microbiology and Biotechnology (IJRSMB), 2016; 2(1): 15-21.

Jamkhande, P. G.; Ajgunde, B. R.; Jadge, D. R. Annona Cherimola mill.(custard apple): A Review on Its Plant Profile, Nutritional Values, Traditional Claims and Ethnomedicinal Properties. Orient. Pharm. Exp. Med. 2017, 17, 189-201

Jaramillo M C, Arango G J, Gonzalez M C, Robledo S M, Velez I D. 2000. Cytotoxicity and antileishmanial activity of Annona muricata pericarp. Fitoterapia 71(2): 183-6. doi: 10.1016/s0367-326x(99)00138-0

Jepkorir M, Ambundo T, Mutuku N, Ndungu J, Njuguna D, Mbugua R, Chepngetich J and Mwitari P (2018). Phytochemical Screening and in vitro Antiproliferative Activity of the Fruit of Annona muricata and Abelmoschus esculentus Pods against Selected Cancer Cell Lines. J. Complem. Altern. Med. Res., 5: 1-11.

Julián-Loaeza, A. P., Santos-Sánchez, N. F., Valadez-Blanco, R., Sánchez-Guzmán, B. S., \& Salas-Coronado, R. (2011). Chemical composition, color, and antioxidant activity of three varieties of Annona diversifolia Safford fruits. Industrial Crops and Products, 34(2), 1262-1268.

Kadir, A., Zorofchian Moghadamtousi, S., Rouhollahi, E., Karimian, H., Ameen Abdulla, M., \& Fadaeinasab, M. (2014). Gastroprotective activity of Annona muricata 
leaves against ethanol-induced gastric injury in rats via Hsp70/Bax involvement. Drug Design, Development and Therapy, 2099.

Kim D H, Ma E S, Suk K D, Son J K, Lee J S, Woo M H. 2001. Annomolin and annocherimolin, new cytotoxic Annonaceous acetogenins from Annona cherimolia seeds. J Nat Prod 64(4): 502-6. doi: 10.1021/np000335u

Kim D H, Son J K, Woo M H. 2001. Annomocherin, Annonacin and annomontacin: a novel and two known bioactive monotetrahydrofuran Annonaceous acetogenins from Annona cherimolia seeds. Arch Pharm Res 24(4): 300-6. doi: 10.1007/BF02975096

Kotkar H M, Mendki P S, Sadan S V, Jha S R, Upasani S M, Maheshwari V L. Antimicrobial and Pesticidal activity of partially purified flavonoids of Annona squamosa. Pest Manag. Sci., 58, 2002, 33-37.

Kuete V, Dzotam J K, Voukeng I K, Fankam A G and Efferth T (2016). Cytotoxicity of methanol extracts of Annona muricata, Passiflora edulis and nine other Cameroonian medicinal plants towards multi-factorial drug-resistant cancer cell lines. Springerplus, 5: 1666p

Li D Y, Yu J G, Zhu J X, Yu D L, Luo X Z, Sun L. 2001. Annonaceous acetogenins of the seeds from Annona muricata. J Asian Nat Prod Res 3(4): 267-76. doi: 10.1080/10286020108040366

Liaw C C, Chang F R, Lin C Y, Chou C J, Chiu H F, Wu M J. 2002. New cytotoxic monotetrahydrofuran Annonaceous acetogenins from Annona muricata. J Nat Prod 65(4): 470-5. doi: 10.1021/np0105578

Liaw C C, Yang Y L, Chen M, Chang F R, Chen S $\mathrm{L}, \mathrm{Wu} \mathrm{S} \mathrm{H}, \mathrm{Wu}$ Y C. Mono-tetrahydrofuran annonaceous acetogenins from Annona squamosa as cytotoxic agent and calcium ion chelators. Journal of Natural Products, 71(5), 2008, 764-771.

Liu, K., Li, H., Yuan, C., Huang, Y., Chen, Y., \& Liu, J. (2015). Identification of phenological growth stages of sugar apple (Annona squamosa L.) using the extended BBCH-scale. Scientia Horticulturae, 181, 76-80.

Liu, N., Yang, H. L., Wang, P., Lu, Y. C., Yang, Y. J., Wang, L., \& Lee, S. C. (2016). Functional proteomic analysis revels that the ethanol extract of Annona muricata L. induces liver cancer cell apoptosis through endoplasmic reticulum stress pathway. Journal of Ethnopharmacology, 189, 210-217.

Luna Jde S, De Carvalho J M, De Lima M R, Bieber L W, Bento Ede S, Franck X. 2006. Acetogenins in Annona muricata L. (Annonaceae) leaves are potent molluscicides. Nat Prod Res 20(3): 253-7. doi: 10.1080/14786410500161445

Martinez-Vazquez M, Estrada-Reyes R, Araujo Escalona A G, Ledesma Velazquez I, Martinez-Mota L, Moreno J. 2012. Antidepressant-like effects of an alkaloid extract of the aerial parts of Annona cherimolia in mice. J Ethnopharmacol 139(1): 164-70. doi: 10.1016/j.jep.2011.10.033

Martinez-Vazquez M, De la Cueva Lozano D G, Estrada-Reyes R, GonzalezLugo N M, Ramirez Apan T, Heinze G. 2005. Bio-guided isolation of the cytotoxic corytenchine and isocoreximine from roots of Annona cherimolia. Fitoterapia 76(7-8): 733-6. doi: 10.1016/j.fitote.2005.08.004

Matsushige A, Kotake Y, Matsunami K, Otsuka H, Ohta S, Takeda Y. 2012. Annonamine, a new aporphine alkaloid from the leaves of Annona muricata. Chem Pharm Bull 60(2): 257-9. doi: 10.1248/cpb.60.257

Matsushige A, Matsunami K, Kotake Y, Otsuka H, Ohta S. 2012. Three new megastigmanes from the leaves of Annona muricata. J Nat Med 66(2): 284-91. doi: 10.1007/s11418-011-05831

Melot A, Fall D, Gleye C, Champy P. 2009. Apolar Annonaceous acetogenins from the fruit pulp of Annona muricata. Molecules 14(11): 4387-95. doi: 10.3390/molecules 14114387

Meira C S, Guimarães E T, Macedo T S, da Silva T B, Menezes L R A, Costa E V. 2014. Chemical composition of essential oils from Annona vepretorum Mart. and Annona squamosa L. (Annonaceae) leaves and their antimalarial and trypanocidal activities. $\mathbf{J}$ Essent Oil Res 27: 160-8. doi: 10.1080/10412905.2014.982876

Mishra, S.; Ahmad, S.; Kumar, N.; Sharma, B. K. Annona muricata (the cancer killer): A Review. Glob. J. Pharm. Res. 2013, 2, 16131618.

Moghadamtousi, S. Z., Rouhollahi, E., Karimian, 
H., Fadaeinasab, M., Firoozinia, M., Abdulla, M. A., et al., (2015c). The chemopotential effect of Annona muricata leaves against azoxymethane-induced colonic aberrant crypt foci in rats and the apoptotic effect of acetogenin annomuricin E in HT-29 cells: a bioassay-guided approach. PLoS ONE 10:e0122288.

doi:

10.1371/journal.pone.0122288

Moghadamtousi, S. Z., Fadaeinasab, M., Nikzad, S., Mohan, G., Ali, H. M., and Kadir, H. A. (2015a). Annona muricata (Annonaceae): a review of its traditional uses, isolated acetogenins and biological activities. Int. J. Mol. Sci. 16, 15625-15658. doi: 10.3390/ijms160715625

M Jepkorir, T Ambundo, C M Ngule, Phytochemical Screening and in vitro Antiproliferative Activity of the Fruit of Annona muricata and Abelmoschus esculentus Pods against Selected Cancer Cell Lines, 2018.

Nawwar M, Ayoub N, Hussein S, Hashim A, ElSharawy R, Wende K. 2012. A flavonol triglycoside and investigation of the antioxidant and cell stimulating activities of Annona muricata Linn. Arch Pharm Res 35(5): 761-7. doi: 10.1007/s12272-012-0501-4.

Nugraha, A. S., Haritakun, R., Lambert, J. M., Dillon, C. T., dan Keller, P. A., 2019. Alkaloids from the Root of Indonesian Annona muricata L. J Nat Prod Res., 2019: 1-9.

Ogunwande I A, Ekundayo O, Olawore N O, Kasali A A. 2006. Essential oil of Annona reticulata $\mathrm{L}$. leaves from nigeria. J Essent Oil Res 18(4): 374-6. doi: 10.1080/10412905.2006.9699117

Oliveira, B. H.; Sant'Ana, A. E. G.; Bastos, D. Z. L. Determination of the diterpenoid, kaurenoic acid, in Annona glabra by HPLC. Phytochem. Anal. 2002, 13, 368-371.

Panda S and Kar A. 2007. Antidiabetic and antioxidative effects of Annona squamosa leaves are possibly mediated through quercetin-3-Oglucoside. BioFactors 31(3-4): 201-10. doi: 10.1002/biof.5520310307

Pieme C A, Kumar S G, Dongmo M S, Moukette B M, Boyoum F F, Ngogang J Y and Saxena A $\mathrm{K}$ (2014). Antiproliferative activity and induction of apoptosis by Annona muricata (Annonaceae) extract on human cancer cells. BMC Complement Altern. Med., 14: 516 p.
Pino J A. 2011. Volatile components of cuban Annona fruits. J Essent Oil Res. 12(5): 613-6. doi: 10.1080/10412905.2000.9712170

Porwal M and Kumar A. 2015. Neuroprotective effect of Annona squamosa and (-) anonaine in decreased GABA receptor of epileptic rats. J Appl Pharm Sci 5: 18-23. doi: 10.7324/JAPS.2015.54.S4

Quílez, A. M.; Fernández-Arche, M. A.; GarcíaGiménez, M. D.; De la Puerta, R. Potential therapeutic applications of the genus Annona: Local and traditional uses and pharmacology. J. Ethnopharmacol. 2018, 225, 244-270.

Ragasa C Y, Soriano G, Torres O B, Don M J, Shen C C. 2012. Acetogenins from Annona muricata. Phcog J 4: 32-7. doi: 10.5530/pj.2012.32.7

Raybaudi-Massilia,R., Jonathan MosquedaMelgar, Alexandra Zambrano and María I. Calderón-Gabaldón. An Analysis In-vitro of the Cytotoxic, Antioxidant and Antimicrobial Activity of Aqueous and Alcoholic Extracts of Annona muricata L. Seed and Pulp. British Journal of Applied Science \& Technology 5(4): $\quad 333-341, \quad 2015, \quad$ Article no.BJAST.2015.031 ISSN: 2231-0843

Saha, R. Pharmacognosy and pharmacology of Annona squamosa. Int. J. Pharm. Life Sci. 2011, 2, 1183-1189.

Singh, Y., Prerak Bhatnagar and Nidhika Thakur. A review on insight of immense nutraceutical and medicinal potential of custard apple (Annona squamosa Linn.). International Journal of Chemical Studies 2019; 7(2): 12371245

Son J K, Kim D H, Woo M H. 2003. Two new epimeric pairs of acetogenins bearing a carbonyl group from Annona cherimolia seeds. J Nat Prod 66(10): 1369-72. doi: 10.1021/np0301487

Sun, S., Liu, J., Zhou, N., Zhu, W., Dou, Q. P., and Zhou, K. (2016). Isolation of three new annonaceous acetogenins from graviola fruit (Annona muricata) and their anti-proliferation on human prostate cancer cell PC-3. Bioorganic Med. Chem. Lett. 26, 4382-4385. doi: 10.1016/j.bmcl.2015.06.038.

Sun S, Liu J, Kadouh H, Sun X, Zhou K. 2014. Three new anti-proliferative Annonaceous acetogenins with mono-tetrahydrofuran ring from graviola fruit (Annona muricata). Bioorg 
Med Chem Lett 24(12): 2773- 6. doi: 10.1016/j.bmcl.2014.03.099

Sun, L. R., H. Zhu, L. S. Gan, J. X. Mo, F. Feng and C. X. Zhou. Constituents from the bark of Annona squamosa and their anti-tumor activity. China J. Chin. Mater. Med. 37: 21002104, 2012

Suresh K, Manoharan S, Vijayaanand M A, Sugunadevi G. Modifying Effects of Annona squamosa on Glycoconjugates Levels in 7,12dimethylbenz (a) Anthracene Induced Hamster Buccal Pouch Carcinogenesis. Journal of Appl. Sci and Res., 6(8), 2010, 973-979.

Suresh, H. M., Shivakumar, B., Hemalatha, K., Heroor, S. S and Hugar, D. S 2011. In vitro anti proliferative activity of Annona reticulata roots on human cancer cell lines. Phcog Res, 3: 9-12.

Syed Najmuddin S U, Romli M F, Hamid M, Alitheen N B and Nik Abd Rahman N M (2016). Anti-cancer effect of Annona muricata Linn Leaves Crude Extract (AMCE) on breast cancer cell line. BMC Complement Altern. Med., 16: $311 \mathrm{p}$

Vila-Nova N S, Morais S M, Falcao M J, Machado L K, Bevilaqua C M, Costa I R. 2011. Leishmanicidal activity and cytotoxicity of compounds from two Annonacea species cultivated in northeastern brazil. Rev Soc Bras Med Trop 44(5): 567-71. doi: 10.1590/s003786822011000500007

Vyas. K, Hansraj Manda, Rahul Kumar Sharma, Gaurav Singhal. An Update Review On Annona squamosa. International Journal of Pharmacy \& Therapeutics, 3(2), 2012, 107118.

Wélé A, Zhang Y, Caux C, Brouard J P, Pousset J L, Bodo B. 2004. Annomuricatin C, a novel cyclohexapeptide from the seeds of Annona Wele A, Mayer C, Dermigny Q, Zhang Y, Blond A, Bodo B. Sequence and three 1 dimensional structure of cycloreticulins A and B new cyclooctapeptides from the seeds of Annona reticulata. Tetrahedron. 2008;64:154-162

Yang, C., Gundala, S. R., Mukkavilli, R., Vangala, S., Reid, M. D., and Aneja, R. (2015). Synergistic interactions among flavonoids and acetogenins in Graviola (Annona muricata) leaves confer protection against prostate cancer. Carcinogenesis 36, 656-665. doi: 10.1093/carcin/ bgv046

Yang Y L, Chang F R, Hwang T L, Chang W T, $\mathrm{Wu}$ Y C. 2004. Inhibitory effects of entkauranes from the stems of Annona squamosa on superoxide anion generation by human neutrophils. Planta Med 70(3): 256-8. doi: 10.1055/s-2004-815544.

Yiallouris A, Patrikios I, Johnson E O, Sereti E, Dimas K, De Ford C, Fedosova N U, Graier W F, Sokratous K, Kyriakou K, Stephanou A (2018) Annonacin promotes selective cancer cell death via NKA-dependent and SERCAdependent pathway. Cells Death Dis 9(7):1-13.

Zorofchian Moghadamtousi, S., Karimian, H., Rouhollahi, E., Paydar, M., Fadaeinasab, M., \& Abdul Kadir, H. (2014). Annona muricata leaves induce G1 cell cycle arrest and apoptosis through mitochondria-mediated pathway in human HCT-116 and HT-29 colon cancer cells. Journal of Ethnopharmacology, 156, 277-289.

Zorofchian Moghadamtousi, S., Rouhollahi, E., Karimian, H., Fadaeinasab, M., Firoozinia, M., Ameen Abdulla, M., \& Abdul Kadir, H. (2015). The Chemopotential Effect of Annona muricata Leaves against AzoxymethaneInduced Colonic Aberrant Crypt Foci in Rats and the Apoptotic Effect of Acetogenin Annomuricin E in HT-29 Cells: A BioassayGuided Approach. PLOS ONE, 10(4), e0122288.

\section{How to cite this article:}

Lusi Madona, Afrizal and Mai Efdi. 2021. Anona Genus : Phytochemical, Anticancer and Activity Structure Relationship. Int.J.Curr.Microbiol.App.Sci. 10(12): 91-110. doi: https://doi.org/10.20546/ijcmas.2021.1012.011 